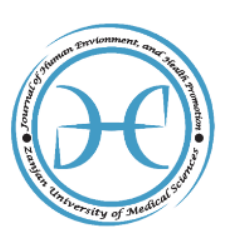

Journal of Human, Environment and Health Promotion

Journal homepage: www.zums.ac.ir/jhehp

\title{
Determination of the Risk Level of Work Posture by REBA and RULA Methods among Workers of Assembly Lines of a Cosmetics Manufacturing Factory
}

\author{
Mojtaba Jafarvand a, Bahare Keshmiri ${ }^{\mathrm{b}}$, Sakineh Varmazyar a, ${ }^{*}$ \\ a Department of Occupational Health Engineering, School of Health, Qazvin University of Medical Sciences, Qazvin, Iran. \\ ${ }^{b}$ Department of Occupational Health, Maryam Hospital, Alborz University of Medical Sciences, Karaj, Iran.
}

${ }^{\star}$ Corresponding author: Sakineh Varmazyar

Department of Occupational Health Engineering, School of Health, Qazvin University of Medical Sciences, Qazvin, Iran.

E-mail address: Svarmazyar@qums.ac.ir

\section{A R T I C L E I N F O}

Article Type:

Original article

Article history:

Received August 28, 2017

Revised October 2, 2017

Accepted October 17, 2017

DOI: $10.29252 /$ jhehp.3.1.2

Keywords:

REBA

RULA

Risk Factor

Ergonomic

Cosmetics

\begin{abstract}
A B S T R A C T
Background: Although the expansion of innovation in the industry has led to an increase in the fast of works, production and productivity, it has also imposed an increase in the incidence of musculoskeletal disorders. So, the aim of this study was determination the risk level of work posture by REBA and RULA method among workers of assembly line of a cosmetic manufacturing factory.

Methods: This study descriptive was carried out among the assembly line workers of a cosmetic manufacturing factory in 2016. Six tasks (including 28 work postures) were selected due to the most risk of inappropriate work posture factor. 18 postures were evaluated by REBA method and 10 postures by RULA method.

Results: The results showed that the highest REBA score (score10) in the hair color manufacturing section and the highest RULA score (score 7) related to the oxidant and powder parts. The minimum score obtained by the REBA and RULA method was 5 and 4 (minimum 2 corrective action level), respectively.

Conclusion: To prevent musculoskeletal disorders and reduce the staff posture score in pouring materials into the mixer or reservoir of manufacturing hair color, oxidant and powder sections, corrective actions such as the use of a pump system for transferring materials to the reservoir and the use of an footrest to avoid lifting the load to a height above the shoulder are recommended.
\end{abstract}

\section{Introduction}

The increasing use of modern technologies in the industry has led to an increase in the fast of work and an increase in production and productivity, but some complications such as fatigue, neuropsychological stress and an increase in the incidence of musculoskeletal disorders have been imposed to human [1].
Work-related musculoskeletal disorders (WMSDS) are including the main causes of workers' discomfort and disability, increased payouts and reduced productivity in industrialized and developing countries, which typically cause widespread involvement in waist, cervical spine and upper limbs (shoulder, elbow, wrists, and fingers) $[2,3]$. 
Musculoskeletal disorders are including the most common occupational diseases and one of the main causes of absenteeism [4]. In the United States, about one million people sick leave for musculoskeletal disorders treatment every year. The economic impact of work-related musculoskeletal disorders in 2001 year is estimated at more than 54 billion dollars [5].

According to the reports of OSHA organization, $42 \%$ all of the occupational diseases are related to awkward posture and musculoskeletal system [6].

According to the report of National Institute of Occupational Health and Safety of the United States, musculoskeletal disorders have devoted themselves to the second rank in terms of importance, frequency, severity and probability of progression among workrelated illnesses [7]. The creation of work-related musculoskeletal disorders is due to excessive biomechanical loads and to individual work patterns [8]. These disorders will be created in any place with excessive force, physical inappropriate condition, frequent repetition of movements and low resting time [9].

Operators who work on assembly lines are including those who require a particular physical condition for a long time. Therefore, because of the pressure induced by these conditions to the musculoskeletal system of these individuals, probably there is a health risk and a feeling of pain and discomfort in various parts of the musculoskeletal system [10].

Although today, with more work done by mechanized machines, the workload on assembly line workers is reduced, the risk of musculoskeletal disorders and cumulative damages is also increased, as mechanized assembly lines increase the speed of the work and the more concentration of forces over small limbs [11].

Musculoskeletal disorders, unlike many of the work-related illnesses that originate from contact with a dangerous substance, is a multifactorial phenomenon which all of the effective factors and risk factors are in four groups include genetic factors, morphology, psychosocial and biomechanical factors [12]. Including the most important biomechanical risk factors in incidence of these disorders, can be refer to force, posture, repetitive movements and duration of work $[13,14]$.

From the important work-related risk factors in incidence of these disorders is work posture (body position while doing the job) which several methods hav2e been proposed to evaluate it. From the presented ergonomic evaluation techniques, the observational methods based on the pen and paper have special merits because no need to specialized equipment and tools as well as the rapid assessment in the short time are of the important features of the two methods Rapid Upper Limb Assessment (RULA) and Rapid Entire Body Assessment (REBA) [14-16].

The Operators are working in assembling lines in the cosmetics industries are including those who require a particular body position for a long time. Therefore, due to the pressure induced by these positions to musculoskeletal system of these people, there is a health risk and a feeling of pain and discomfort in different parts of the musculoskeletal system $[5,10]$.

The aim of this study was to determination of the risk level of work posture by REBA and RULA methods among workers of assembly lines of a cosmetics manufacturing factory.

\section{Materials and Methods}

There were 6 production and manufacturing lines in the cosmetics factory: making oxidant (with 5 workers), packing oxidants (with 5 workers), crating powder (with 1 worker), powder packing (with 5 workers), making hair color (with 2 workers) and packing the hair color (with 5 workers). In order to identify jobs and related- subtasks was helped from supervisors, officials and employed workers in the relevant section.

In this descriptive study, 6 tasks were studied, which led to a total of 28 work postures in 50 parts of the manufactory. These tasks include carrying, lifting, packing and handling packages. Then analysis of each task was performed using observational method (filming). The REBA and RULA methods were used to assess the risk of musculoskeletal disorders in relation to the risk factors of each posture. In the REBA method, different parts of the body are put in the two groups A and B for analysis, respectively the position of the waist, neck and legs with a total of 60 combined posture and the position of the arms, forearms and wrists with a total of 36 combined postures. Then to A score, add force/load score and to B score add coupling score and finally to $\mathrm{C}$ score obtained from A, B, add activity score and therefore generating a single score that represents the level of MSD risk (Table 1).

In the RULA method, regions of the body are also divided into two groups: A (arm, forearm, wrists, and wrist rotation) and B (neck, trunk and foot). After the 
scores of A and B were obtained, the score of work load and the score of using muscle are calculated separately for both groups [14].

Table 1: Final REBA score

\begin{tabular}{cc}
\hline Score & Level of MSD Risk \\
\hline 1 & Negligible risk, no action required \\
$2-3$ & Low risk, change may be needed \\
$4-7$ & Medium risk, further investigation, change soon \\
$8-10$ & High risk, investigate and implement change \\
$11+$ & Very high risk, implement change \\
\hline
\end{tabular}

That way the scores $\mathrm{C}$ and $\mathrm{D}$ and ultimately the final score are obtained respectively (Table 2). A total of 18 work postures were studied in REBA method and 10 postures were evaluated by RULA method. According to the specific corrective action level of both methods, corrective priorities were determined for 28 postures.

In the tasks that were more work sitting, used from RULA method and in the tasks that were more load handling activities and gripping the load, used from REBA method.

Table 2: Final RUAL score

\begin{tabular}{ccc}
\hline Score & Action level & Description \\
\hline 1 or 2 & 1 & Acceptable \\
3 or 4 & 2 & Investigate further \\
5 or 6 & 3 & Investigate further and change soon \\
7 & 4 & Investigate and change immediately \\
\hline
\end{tabular}

\section{Results and Discussion}

The results obtained from the evaluation by REBA, RULA and corrective action level for each of the tasks are presented in Tables 1 and 2. According to Table 3, the most tasks performed in the packaging of hair color and oxidant obtained the average level of risk, and the tasks of making and packing powder had a high risk level.

The results of Table 4 show that the highest level of corrective actions are in the tasks performed in the manufacture sections of powder and oxidants, respectively, and the smallest them are in the manufacture and packaging sections of hair color, packaging of powder and oxidant.

According to Table 1, the evaluation of each task in the REBA method shows that the highest score ( 9 and 7) is related to the sub-task or the posture of lifting bags from the ground and removing cartons from the table and the ground in the section of production and packaging of oxidants due to excessive bending in and inappropriate grip when lifting the load. Increasing the score in these sub-tasks can be due bending over 20 degrees along with rotation to the sides in the neck region (sore 3), bending 20-60 degrees along with twist or bending over 60 degrees in region of the trunk (score 4 or 3 ), and bending between 20-45 degree along with up or abduction in the upper arm region (score 3 or 2).

The highest score in the powder packing task is to remove the carton from the table with its opening and adhering operation (score 9), as well as in the task of making and packing the hair color in the sub tasks of pouring the materials into the mixer (score 10) and removing the carton from the ground and opening it (score 9), due to excessive bending in the neck, trunk, and deviations in different parts of the hand. Obtaining a score of 9 or 10 in these sub-tasks can be due bending over 20 degrees with rotation to the sides in the neck region, bending over 60 degrees in the trunk region and locate upper arm in position of 45-90 degrees or 20-45 along with abduction or it. A study done by Marjan Eidzadeh et al in 2015 is in line with this study in terms of the final score of the REBA method in similar tasks in a date-packing plant [17].

Table 2 shows that the highest final score (score 7) of the RULA method is related to the task of making oxidants and powders in sub-tasks of pouring material into the tank, pouring the raw materials into the mixer and pouring potassium and ammonium, and irozil and paraffin in the mill and add it to the mixer. High score in the above tasks can be due to bending over 20 degrees or bending 10-20 degrees along with twist and bending to the sides in the neck region and bending 2060 degrees in truck, deviation 15 degrees in wrist region and bending 20-45 in upper arm. Inappropriate postures and thereupon increased local pressure on the muscles of the body, as well as lifting the load at a height above the shoulder in each of the tasks are the reasons for the highest score in mentioned subtasks which are in line with the study of Seraji and et al. in 2007 in terms of the corresponding remedial action in some of the tasks [18]. Also corresponds with Deepak SHARAN et al.'s findings, by selecting 9 tasks (36 subtasks) for evaluation, in a cosmetic company (2014) 
Table 3: Results of evaluation by REBA method

\begin{tabular}{|c|c|c|c|c|}
\hline Task or work posture & Working posture & Final score REBA & Risk level & Corrective action \\
\hline \multirow{2}{*}{ Making oxidant } & Lifting bags from the ground & 9 & High & Urgently needed \\
\hline & Cleaning the Tanks & 5 & Medium & Is essential \\
\hline \multirow{3}{*}{ Packing oxidants } & $\begin{array}{l}\text { Picking up cartons from the ground } \\
\text { and opening It }\end{array}$ & 7 & Medium & Is essential \\
\hline & To place the bottle inside the carton & 5 & Medium & Is essential \\
\hline & Carton arranging in the pallet & 6 & Medium & Is essential \\
\hline \multirow{3}{*}{ Creating powder } & Removing cartons from the table & 7 & Medium & Is essential \\
\hline & $\begin{array}{c}\text { Crushing potassium and ammonium } \\
\text { with a rod }\end{array}$ & 8 & High & Is urgently needed \\
\hline & Putting cartons on the pallet & 5 & Medium & Is essential \\
\hline \multirow{3}{*}{ Powder packaging } & Putting bottles in cartons & 8 & High & Is urgently needed \\
\hline & $\begin{array}{l}\text { Removing cartons from the table and } \\
\text { inserting it into the adhesive part }\end{array}$ & 9 & High & Urgently needed \\
\hline & $\begin{array}{l}\text { Removing cartons from the ground } \\
\text { and opening It }\end{array}$ & 9 & High & Urgently needed \\
\hline \multirow{2}{*}{ Making hair color } & Washing the tanks & 5 & Medium & Is essential \\
\hline & Pouring material into the mixer & 10 & High & Is Urgently needed \\
\hline \multirow{5}{*}{ Packing the hair color } & Removing a tube box from the table & 6 & Medium & Is essential \\
\hline & Putting the box on the color machine & 5 & Medium & Is essential \\
\hline & $\begin{array}{c}\text { Removing cartons from the inside of } \\
\text { the carton and placing it inside the } \\
\text { device }\end{array}$ & 5 & Medium & Is essential \\
\hline & $\begin{array}{c}\text { Removing the carton from the ground } \\
\text { and opening it }\end{array}$ & 9 & High & Is Urgently needed \\
\hline & Picking cartons on the pallet & 6 & Medium & Is essential \\
\hline
\end{tabular}


Table 4: The results of the RULA assessment

\begin{tabular}{|c|c|c|c|c|}
\hline Task & Working posture & Final score RULA & Action level & Description \\
\hline Making oxidant & $\begin{array}{l}\text { Pouring material into the } \\
\text { reservoir } \\
\text { Pouring material into the } \\
\text { reservoir with pump }\end{array}$ & 70 & 2 & $\begin{array}{c}\text { Investigations and changes are required } \\
\text { as soon as possible } \\
\text { More inspections and some changes are } \\
\text { needed }\end{array}$ \\
\hline \multirow[t]{2}{*}{ The oxidation package } & $\begin{array}{l}\text { Placing the bottle on the } \\
\text { roll as sitting }\end{array}$ & 5 & 3 & $\begin{array}{l}\text { Ergonomic examinations and changes } \\
\text { are needed }\end{array}$ \\
\hline & $\begin{array}{l}\text { Pouring raw materials into } \\
\text { the mixer }\end{array}$ & 7 & 4 & $\begin{array}{c}\text { Investigations and changes are required } \\
\text { soon }\end{array}$ \\
\hline \multirow[t]{2}{*}{ Making powder } & $\begin{array}{l}\text { Pouring Potassium, } \\
\text { Ammonium and Paraffin } \\
\text { Inside the Mill and Adding } \\
\text { it to the Mixer }\end{array}$ & 7 & 4 & $\begin{array}{c}\text { Investigations and Changes are } \\
\text { Required Soon }\end{array}$ \\
\hline & $\begin{array}{l}\text { Emptying the Powder in } \\
\text { the Bucket and Pouring } \\
\text { into the Barrel }\end{array}$ & 4 & 2 & $\begin{array}{l}\text { More Inspections and some Changes are } \\
\text { Needed }\end{array}$ \\
\hline \multirow[b]{2}{*}{ Powder Packing } & $\begin{array}{l}\text { Removing the Bottle from } \\
\text { the Table andPutting it } \\
\text { under the Filler }\end{array}$ & 4 & 2 & $\begin{array}{l}\text { More Inspections and some Changes are } \\
\text { Needed }\end{array}$ \\
\hline & $\begin{array}{l}\text { Removing the Bottle from } \\
\text { Filler and Putting the Bottle } \\
\text { on the Roll }\end{array}$ & 6 & 3 & $\begin{array}{l}\text { Ergonomic Examinations and Changes } \\
\text { are Needed }\end{array}$ \\
\hline Making Hair Color & $\begin{array}{l}\text { Pumping Material into } \\
\text { Tanks }\end{array}$ & 4 & 2 & $\begin{array}{l}\text { More Inspections and some Changes are } \\
\text { Needed }\end{array}$ \\
\hline Hair Color Packaging & $\begin{array}{l}\text { Hair Color Putting Inside } \\
\text { the Carton }\end{array}$ & 4 & 2 & $\begin{array}{l}\text { More Inspections and some Changes are } \\
\text { Needed }\end{array}$ \\
\hline
\end{tabular}




\section{Conclusion}

Based on the obtained results, it was found that the risk level of the Work-related musculoskeletal disorders (WMSDS) based on REBA and RULA methods showed that the working environment conditions are damaging. The REBA and RULA scores were high in subtasks of manufacturing sections of the hair color, oxidants and powder in the pouring of materials into the mixer or reservoir. Corrective actions, such as the use of a pump system, are recommended for the transfer of materials into the tank and the use of an underfoot with an appropriate cross-section to avoid lifting the load to a height above the shoulder and so that preventing musculoskeletal disorders and reducing the posture score of workers in the parts. Also, putting up cartons in an appropriate height from the ground level can prevent from bending more than in truck region.

\section{References}

1. Mirmohammadi S, Mehrparvar A, Soleimani H, Lotfi MH, Akbari H, Heidari N. Musculoskeletal Disorders among Video Display Terminal (VDT) Workers Comparing with other Office Workers. Iran Occup Health J. 2010; 7(2): 11-4.

2. Mottaghi MBM MR, Rohani Z, Basiri Moghadam K, Irani H. The Survey of Prevalence of Vertebral Column Pain and Some Related Factors in Nurses Employed in Gonabad Hospitals. J Gonabad Univ Med Sci. 2011; 17(4): 51-7.

3. Gordon C, Johnson EW, Gatens PF, Ashton JJ. Wrist Ratio Correlation with Carpal Tunnel Syndrome in Industry. Am J Phys Med Rehabil. 1988; 67(6): 270-2.

4. Mohammadfam I, Kianfar A, Afsartala B. Assessment of Musculoskeletal Disorders in a Manufacturing Company Using QEC and LUBA Methods and Comparing the Results. Iran Occup Health J. 2010; 7(1): 54-60.

5. Rowshani Z, Khavanin A, Mirzaei R, Mohseni M. Evaluating the Potential of Terminal Sections of Upper Extremity Musculoskeletal Disorders in an Electronic Company. J Qazvin Med Sci. 2013; 17(2): 25-32.

6. Rowshani Z, Khavanin A, Mirzaei R, Mohseni M. Comparing RULA and Strain Index Methods for the Assessment of the Potential Causes of Musculoskeletal Disorders in the Upper Extremity in an Electronic
Company in Tehran. J Kashan Univ Med Sci. 2012; 17(1): 61-70.

7. Mostaghaci M, Davari MH, Mollaei F, Salehi M, Mehrparvar AH. Frequency of Work-Related Musculoskeletal Disorders and to Assess Posture as RULA in the Automobile Industry Workers. Occup Med. 2011; 3(4-6): 26-32.

8. Mattioli S, Brillante R, Zanardi F, Bonfiglioli R. Occupational (and Non-Occupational) Risk Factors for Musculoskeletal Disorders. Med Lav. 2005; 97(3): 52934.

9. Fathallah FA. Musculoskeletal Disorders in LaborIntensive Agriculture. Appl Ergon. 2010; 41(6): 738-43.

10. Kamalinia M, Nasl Saraji G, Choobine A, Hosseini M, Kee D. Postural Loading on Upper Limbs in Workers of the Assembly Line of an Iranian Telecommunication Manufacturing Company Usingthe LUBA Technique. Scientific J School of Public Health and Institute of Public Health Res. 2009; 6(3-4): 49-60.

11. Putz-Anderson V. Cumulative Trauma Disorders: A Manual for Musculoskeletal Diseases of the Upper Limbs. Putz-Anderson, Vern; 1988.

12. Choobineh A TS, Behzadi M. Musculoskeletal Problems among Workers of an Iranian Sugar-Producing Factory. Int J Occup Saf Ergon. 2009; 15(4): 419-24.

13. Choobineh A, Rahimifard H, Jahangiri M, Mahmoodkhani S. Musculoskeletal Injuries and Their Associated Risk Factors in Office Workplaces. Iran Occup Health J. 2012; 8(4).

14. Choobineh A. Posture Assessment Methods in Occupational Ergonomics. 2 Editor. Tehran: Publications: Fanavaran; 2007.

15. Steven Moore J, Garg A. The Strain Index: A Proposed Method to Analyze Jobs for Risk of Distal Upper Extremity Disorders. Am Industrial Hyg Association. 1995; 56(5): 443-58.

16. Nasle Seraji J, Ghafari Soto Bady M, Shahtaheri SJD. Investigation of Correlation Results of Two Evaluation Methods REBA \& RULA Regarding Risk Factors for Work-Related Musculoskeletal Disorders. Iran Occup Health. 2006; 3(2): 0-5.

17. Eidizadeh M. Ergonomic Evaluation of the Posture of Dates Packinghouse Workers by REBA Method. Agric J. 2014; 37(1).

18. Nasl Saraji J, Ghaffari M, Shahtaheri S. Survey of Correlation between Two Evaluation Method of Work 
Related Musculoskeletal Disorders Risk Factors REBA\& RULA. Iran Occup Health. 2006; 3(2): 5-0.

19. Sharan D, Mohandoss M, Ranganthan R, JOSE JA,
Rajkumar JS. Biomechanical Risk Factors among the Assembly Line Workers of a Cosmetics Manufacturing Factory in India. Hum Factors Organ Des Manag. 2014; 46(1): 1027-31. 